\title{
Bifunctional Derivative of p,p'-Dichlorochalcone. Part II. Synthesis of a Novel Compound 2-[2-Carboxymethylthio-2-(4-chlorophenyl)ethyl]-2-(4- chlorophenyl)-4-thiazolidinone
}

\author{
Sayeed Mukhtar ${ }^{1}$, Mujeebur Rahman V.P. ${ }^{1}$, Wajid Husain Ansari* ${ }^{1}$, Guy Lemière ${ }^{2}$, Alex De \\ Groot $^{2}$ and Roger Dommisse ${ }^{2}$ \\ ${ }^{1}$ Department of Chemistry, Aligarh Muslim University, Aligarh-202002, India \\ E-mail: cht09wha@amu.up.nic.in \\ ${ }^{2}$ Department of Chemistry (Natural Products), University of Antwerp (RUCA), Groenenborgerlaan \\ 171, B-2020 Antwerp, Belgium \\ Fax: (internet.) +32-3-2180233, E-mail: lemiere@ ruca.ua.ac.be
}

*Author to whom correspondence should be addressed.

Received: 3 March 1999 / Accepted: 10 June 1999 / Published: 19 July 1999

\begin{abstract}
The synthesis of 2-[2-carboxymethylthio-2-(4-chlorophenyl) ethyl]-2-(4chlorophenyl) - 4-thiazolidinone (1) from p, p'- dichlorochalcone using thioglycollic acid in the presence of ammonium carbonate is described. Structural assignment and stereochemistry are discussed.
\end{abstract}

Keywords: Organic synthesis, chalcone, thiazolidinone, ${ }^{1} \mathrm{H}-\mathrm{NMR},{ }^{13} \mathrm{C}-\mathrm{NMR}$.

\section{Introduction}

4-Thiazolidinones substituted in the 2-position, (-)-2-(5-carboxypentyl)-4-thiazolidinone, its derivatives and analogues [1] exhibit unusually high in vitro activity against Mycobacterium tuberculosis. Recently, a number of 2-pyridyl substituted 4-thiazolidinones has been synthesised and found to exhibit highly potent and selective anti-Platelet Activating Factor activity both in vitro and in

(C) 1999 by the authors. Reproduction of this article, by any means, is permitted for noncommercial purposes. 
vivo [2]. As part of our aim in search of biologically active compounds with sulphur and nitrogen containing heterocycles, we have synthesised a 2-substituted tetrahydro-1,3-thiazin-4-one [3] (its biological screening is under study [4]). Because 4-thiazolidinones substituted in the 2 position were proven to be biologically very potent and selective [1-2], we extended our work on the synthesis of 2[2-carboxymethylthio-2-(4-chlorophenyl)ethyl]-2-(4-chlorophenyl)-4-thiazolidinone (1), a novel compound, from p,p'-dichlorochalcone (2) using thioglycollic acid in the presence of ammonium carbonate.

\section{Results and Discussion}

We report here the synthesis of compound (1) in two ways (Scheme 1):

(i) - a mixture of chalcone (2), thioglycollic acid and ammonium carbonate (molar ratio (1:2.5:5) in dry benzene was refluxed for $35 \mathrm{~h}$. Purification of the products by column chromatography over silicagel followed by crystallisation afforded compound (1) as colourless globules in good yield (65\%).

(ii-a) - a mixture of chalcone (2) and thioglycollic acid (molar ratio 1:1.25) in dry benzene was refluxed for $2 \mathrm{~h}$; the reaction mixture on crystallisation gave colourless needles of thioether (3) in $77 \%$ yield.

(ii-b) - the thioether (3) in dry benzene was then refluxed with thioglycollic acid and ammonium carbonate (molar ratio $1: 1.25: 5$ ) for $32 \mathrm{~h}$ and the products on purification as above furnished compound (1) (64\%).

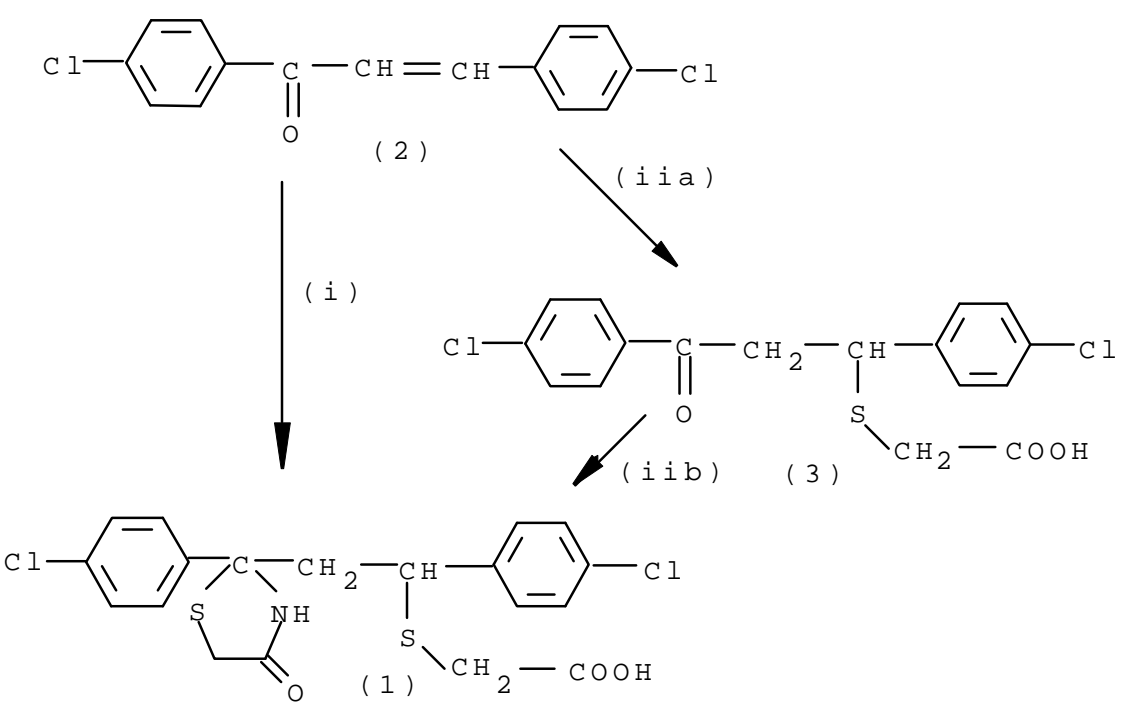

Scheme 1. Synthesis of (1). (i) (2): $\mathrm{HSCH}_{2} \mathrm{COOH}$ : $\left(\mathrm{NH}_{4}\right)_{2} \mathrm{CO}_{3}$ (molar ratio 1:2.5:5), dry benzene, reflux, 35h. (ii-a) (2): $\mathrm{HSCH}_{2} \mathrm{COOH}$ (molar ratio 1:1.25), dry benzene, reflux, 2h. (ii-b) (3):

$\mathrm{HSCH}_{2} \mathrm{COOH}:\left(\mathrm{NH}_{4}\right)_{2} \mathrm{CO}_{3}$ (molar ratio 1: 1.25:5), dry benzene, reflux, 32h.

The constitution of (1) is confirmed by ${ }^{1} \mathrm{H}-\mathrm{NMR},{ }^{13} \mathrm{C}-\mathrm{NMR}$, INEPT, COSY, HETCOR and longrange-HETCOR spectra (Tables 1 and 2). These spectra and an additional NOE-experiment also 
suggest that the relative configuration of product (1) is most probably $u$ (unlike [5]), and the partial conformation of both central bonds C-2-C-1' and C-1'-C-2 ' is antiperiplanar (Figure 1 [6]).

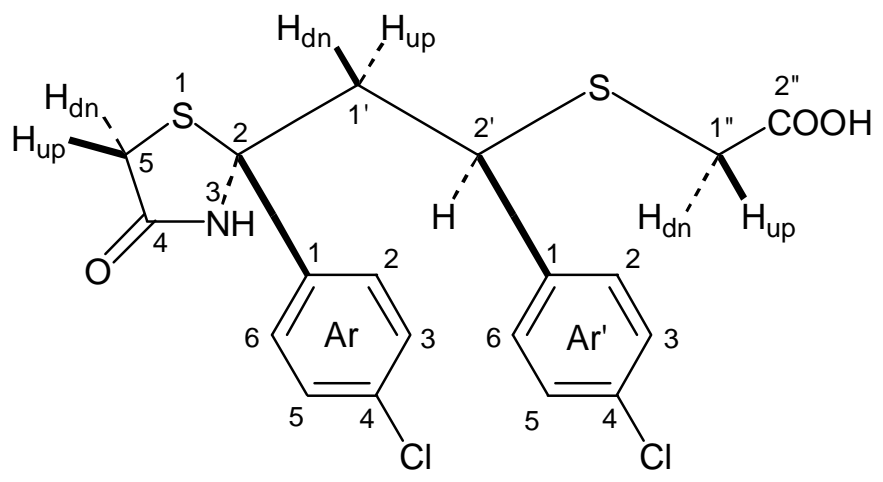

Figure 1.

Table 1. ${ }^{1} \mathrm{H}-\mathrm{NMR}$ data of (1).

\begin{tabular}{|c|c|c|c|c|c|}
\hline $\mathrm{H}-\mathrm{nr}$ & $\delta(\mathrm{ppm})$ & Integration & Multiplicity & $\mathrm{J}(\mathrm{Hz})$ & NOE \\
\hline $5_{\text {up }}$ & 3.42 & $1 \mathrm{H}$ & $\mathrm{d}$ & $\mathrm{J}_{\text {5u, }, \text { dn }} 15.56$ & \\
\hline $5_{\mathrm{dn}}$ & 3.59 & $1 \mathrm{H}$ & d & $\mathrm{J}_{5 \mathrm{up}, 5 \mathrm{dn}} 15.56$ & \\
\hline $\mathrm{NH}$ & 9.20 & $1 \mathrm{H}$ & $\mathrm{s}$ & - & Ar- 2,$6 ; 2^{\prime}$ \\
\hline $1_{\text {up }}^{\prime}$ & 2.66 & $1 \mathrm{H}$ & dd & 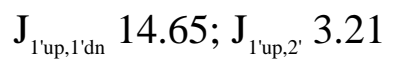 & \\
\hline $1_{\mathrm{dn}}^{\prime}$ & 2.82 & $1 \mathrm{H}$ & dd & $\mathrm{J}_{1^{\prime} \text { up }, 1^{\prime} \mathrm{dn}} 14.65 ; \mathrm{J}_{1^{\prime} \mathrm{dn}, 2^{\prime}} 9.46$ & \\
\hline $2^{\prime}$ & 4.14 & $1 \mathrm{H}$ & dd & $\mathbf{J}_{1^{\prime} \text { up }, 2^{\prime}} 3.21 ; \mathbf{J}_{1^{\prime} \text { dn, } 2^{\prime}} 9.46$ & \\
\hline $1 "_{\text {up }}$ & 2.85 & $1 \mathrm{H}$ & $d$ & $\mathrm{~J}_{\text {1"up,1"dn }} 15.26$ & \\
\hline $1{ }_{\mathrm{dn}}^{\prime \prime}$ & 3.04 & $1 \mathrm{H}$ & $d$ & $\mathrm{~J}_{\text {l"up,l"dn }} 15.26$ & \\
\hline Ar-2,6 & 7.29 & $2 \mathrm{H}$ & $d$ & $\mathrm{~J}_{\mathrm{Ar}-2,6, \mathrm{Ar}-3,5} 8.85$ & $1_{\text {up }}^{\prime}, 1_{\text {dn }}^{\prime}, 2^{\prime}, \mathrm{NH}$ \\
\hline Ar-3,5 & 7.23 & $2 \mathrm{H}$ & $d$ & $\mathrm{~J}_{\mathrm{Ar}-2,6, \mathrm{Ar}-3,5} 8.85$ & \\
\hline Ar'-2,6 & 7.13 & $2 \mathrm{H}$ & $\mathrm{d}$ & $\mathrm{J}_{\mathrm{Ar}^{\prime}-2,6, \mathrm{Ar}-3,5} 8.55$ & $1_{\mathrm{dn}}^{\prime}, 2^{\prime}, 1_{\text {up }}^{\prime \prime}$ \\
\hline Ar'-3,5 & 7.20 & $2 \mathrm{H}$ & $\mathrm{d}$ & $\mathrm{J}_{\Delta r^{\prime}-26 \Delta r^{\prime}-3.5} 8.55$ & \\
\hline
\end{tabular}

Especially the ${ }^{1} \mathrm{H}-\mathrm{NMR}$ spectrum contains stereochemical information. Both the diastereotopic hydrogen atoms as well at C-1" as at C-5 are well separated from each other, one hydrogen atom of each pair, $\mathrm{H}_{\text {up }}$, being above the phenyl ring in the shielding cone and the other one, $\mathrm{H}_{\mathrm{dn}}$, outside of it. Also the diastereotopic hydrogen atoms at C-1' are well separated. According to Karplus [8] the coupling constants reveal an antiperiplanar torsion angle for $\mathrm{H}_{\mathrm{dn}}-1^{\prime}$ and $\mathrm{H}-2$ ', and a synclinal torsion angle for $\mathrm{H}_{\text {up }}-1^{\prime}$ and $\mathrm{H}-2$ '. Further, irradiation of the NH-proton results in a NOE-enhancement of H-Ar2,6, but also of $\mathrm{H}-2^{\prime}$ which means that the $\mathrm{NH}$-proton and $\mathrm{H}-2^{2}$ are very near to each other. Irradiation 
of $\mathrm{H}-\mathrm{Ar}^{\prime}-2,6$ activates $\mathrm{H}-2$ ', but also $\mathrm{H}_{\mathrm{dn}}-1^{\prime}$ and $\mathrm{H}_{\mathrm{up}}-1$ ", which means that also these protons are very near to each other. Molecular mechanics calculations confirm that the structure as shown in figure 1 is the most stable form of compound (1).

Table 2. ${ }^{13} \mathrm{C}-\mathrm{NMR}$ data of (1).

\begin{tabular}{|c|c|c|c|}
\hline C-nr & $\begin{array}{l}\delta \\
(\mathrm{ppm})\end{array}$ & INEPT & $\begin{array}{l}\text { Longe-range HETCOR } \\
\text { correlation with }\end{array}$ \\
\hline 2 & 69.30 & $\mathrm{C}$ & $\mathrm{H}-\mathrm{Ar}-2,6 ; \mathrm{H}-1_{\text {up }}^{\prime} ; \mathrm{H}-2^{\prime} ; \mathrm{NH}$ \\
\hline 4 & 172.45 & $\mathrm{C}$ & $\mathrm{H}-5_{\mathrm{up}} ; \mathrm{H}-5_{\mathrm{dn}}$ \\
\hline 5 & 32.91 & $\mathrm{CH}_{2}$ & $\mathrm{NH}$ \\
\hline $1^{\prime}$ & 49.08 & $\mathrm{CH}_{2}$ & \\
\hline $2^{\prime}$ & 44.52 & $\mathrm{CH}$ & $\mathrm{H}-\mathrm{Ar}-2,6 ; \mathrm{H}-1{ }_{\mathrm{up}} ; \mathrm{H}-1_{\mathrm{dn}}$ \\
\hline $1 "$ & 32.91 & $\mathrm{CH}_{2}$ & \\
\hline $2^{\prime \prime}$ & 170.70 & $\mathrm{C}$ & $\mathrm{H}-1{ }_{\mathrm{up}} ; \mathrm{H}-1_{\mathrm{dn}}$ \\
\hline Ar-1 & 143.41 & $\mathrm{C}$ & H-Ar-3,5 \\
\hline Ar-2,6 & 126.79 & $\mathrm{CH}$ & H-Ar-2,6 \\
\hline Ar-3,5 & $127.78^{\mathrm{a}}$ & $\mathrm{CH}$ & H-Ar-3,5 \\
\hline Ar-4 & 131.84 & $\mathrm{C}$ & H-Ar-2,6 \\
\hline Ar'-1 & 139.93 & $\mathrm{C}$ & H-Ar'-3,5; H-1' \\
\hline Ar'-2,6 & 129.87 & $\mathrm{CH}$ & H-Ar-2,6; H-2' \\
\hline Ar'-3,5 & $127.86^{\mathrm{a}}$ & $\mathrm{CH}$ & H-Ar'-3,5 \\
\hline Ar'-4 & 131.28 & $\mathrm{C}$ & H-Ar'-2,6 \\
\hline
\end{tabular}

${ }^{a}$ Assignment may be reversed.

\section{Experimental}

Melting points were determined on a Koffler hot-plate apparatus and are uncorrected. IR spectra were recorded on a Perkin Elmer 621 spectrophotometer; ${ }^{1} \mathrm{H}$ - and ${ }^{13} \mathrm{C}-\mathrm{NMR}$ spectra were recorded on a Varian Unity 400 spectrometer and DCI-mass spectra with a Ribermag R10-10B quadrupole mass spectrometer. Reagents and solvents were of commercial grade and were used without further purification. Column chromatography was performed on Silica Gel 60 (120 mesh) (194013).

p,p'-Dichlorochalcone (2) was prepared following a published but slightly modified procedure [9] by condensing $p$-chloroacetophenone with $p$-chlorobenzylidene diacetate (both prepared according to reported procedures [10]) in equimolar ratio in the presence of 2.5 equivalents of sodium hydroxide as light yellow crystalline needles in $85 \%$ yield, m.p. $156^{\circ} \mathrm{C}$, Rf 0.72 (petroleum ether $\left(40-60^{\circ}\right)$ : benzene $-1: 1 \mathrm{v} / \mathrm{v})$. 


\section{2-[2-Carboxymethylthio-2-(4-chlorophenyl)ethyl]-2-(4-chlorophenyl)-4-thiazolidinone(1)}

(i) A mixture of p,p'-dichlorochalcone (2) (570mg, $2.06 \mathrm{mmol}$ ), thioglycollic acid (474 mg, 5.15 $\mathrm{mmol}$ ) and ammonium carbonate $(989 \mathrm{mg}, 10.3 \mathrm{mmol})$ in dry benzene $(20 \mathrm{ml})$ was refluxed for $35 \mathrm{~h}$ with stirring, and collecting the generated water in an azeotropic collector. The solution was then cooled, washed with water and the organic phase dried over $\mathrm{Na}_{2} \mathrm{SO}_{4}$. The solvent was distilled off under reduced pressure and the orange oily residue left was chromatographed over a silicagel column (pet. ether $\left(40-60^{\circ}\right)$ : diethyl ether $3: 7 \mathrm{v} / \mathrm{v}$ ). The solid product (light orange) obtained was recrystallised from benzene-acetone yielding (1) as white crystalline globules, $590 \mathrm{mg}(64.9 \%)$, m.p. $205^{\circ} \mathrm{C}$, Rf 0.19 (pet. ether $\left(40-60^{\circ}\right)$ : diethyl ether - 3:7 v/v).

(ii-a) A solution of p,p'-dichlorochalcone (2) (850 mg, $3.07 \mathrm{mmol}$ ) and thioglycollic acid (355 $\mathrm{mg}$, $3.84 \mathrm{mmol})$ in dry benzene $(25 \mathrm{ml})$ was refluxed for $2 \mathrm{~h}$, cooled, washed with water and the organic layer dried over $\mathrm{Na}_{2} \mathrm{SO}_{4}$. The white solid obtained on evaporation of the solvent was crystallised from benzene to furnish white crystalline needles (3), $870 \mathrm{mg}(76.9 \%)$, m.p. $116^{\circ} \mathrm{C}$, Rf 0.84 (pet. ether (40$60^{\circ}$ ) : diethyl ether $3: 7 \mathrm{v} / \mathrm{v}$ ).

(ii-b) To a solution of the thioether $(3)(450 \mathrm{mg}, 1.22 \mathrm{mmol})$ in dry benzene $(15 \mathrm{ml})$ was added thioglycollic acid $(140 \mathrm{mg}, 1.52 \mathrm{mmol})$ and ammonium carbonate $(585 \mathrm{mg}, 6.1 \mathrm{mmol})$. This mixture was refluxed for $32 \mathrm{~h}$. The products on usual workup and crystallisation gave (1) as white crystalline globules, $340 \mathrm{mg}(64 \%)$, m.p. $205^{\circ} \mathrm{C}$, Rf 0.19 (pet. ether $\left(40-60^{\circ}\right)$ : diethyl ether - 3:7 v/v).

IR (KBr) : $v_{\max } 3400(\mathrm{NH}), 3150(-\mathrm{OH}), 1720(-\mathrm{COOH}), 1670$ (-CONH-), 1610, 1590 (phenyl), $1480\left(\mathrm{~S}_{-} \mathrm{CH}_{2}\right), 1410(\mathrm{C}-\mathrm{N}), 1270,1080,1000,820 \mathrm{~cm}^{-1}$ - DCI-MS (NH3) : m/z 442/444/446 [M+1].

Acknowledgements: We thank Prof. M. Ilyas for providing necessary facilities and Prof. M.S. Ahmad for helpful discussions.

\section{References and Notes}

1. (a) McLamore, W.M.; Celmer, W.D.; Bogert, V.V.; Pennington, F.C.; Solomons, I.A. J. Am. Chem. Soc. 1952, 74, 2946. (b) Sobin, B.A. J. Am. Chem. Soc. 1952, 74, 2947. (c) McLamore, W.M.; Celmer, W.D.; Bogert, V.V.; Pennington, F.C.; Sobin, B.A.; Solomons, I.A. J. Am. Chem. Soc. 1953, 75, 105. (d) Pennington, F. C.; Celmer, W. D.; McLamore, W.M.; Bogert, V.V.; Solomons, I.A. J. Am. Chem. Soc. 1953, 75, 109.

2. Tanabe, Y.; Yamamoto, H.; Murakami, M.; Yanagi, K.; Kubota, Y.; Okumura, H.; Sanemitsu , Y.; Suzukamo, G. J. Chem. Soc. Perkin Trans I 1995, 7, 935.

3. Khatoon, F.; Pachauri R.; Ansari, W.H. J. Indian Chem. Soc. 1997, 74, 417.

4. National Cancer Institute, Bethesda, Maryland (Development therapeutic program in vitro NSC No. 703776).

5. Basic Terminology of Stereochemistry (IUPAC Recommendations 1996), 
http://www.chem.qmw.ac.uk/iupac/stereo/

6. The relative configuration of (1) is depicted according to a proposal of Maehr H. [7].

7. Maehr, H. J. Chem. Ed. 1985, 62, 114.

8. Karplus, M. J. Chem. Phys. 1959, 30, 11.

9. Davey, W.; Gwilt, J. R. J. Chem. Soc. 1957, 1008.

10. A.I. Vogel "A Text Book of Practical Organic Chemistry", Longman London, 4th edition, 1978.

Sample Availability: Available from the authors.

(C) 1999 by the authors. Reproduction of this article, by any means, is permitted for noncommercial purposes. 